\title{
THE DEMONSTRATION AND LOCALIZATION OF RENAL TUBULAR REABSORPTION OF HEMOGLOBIN BY STOP FLOW ANALYSIS *
}

\author{
By WILLOUGHBY LATHEM, BERNARD B. DAVIS, $\dagger$ PAUL H. ZWEIG AND \\ ROBERT DEW
}

\begin{abstract}
(From the Department of Medicine, University of Pittsburgh School of Medicine,
\end{abstract} Pittsburgh, Pa.)

(Submitted for publication December 10, 1959; accepted February 4, 1960)

The evidence that extracorpuscular hemoglobin is reabsorbed by renal tubular cells after filtration through the glomerulus is based principally upon morphological studies. In a variety of animal species hemoglobin or its metabolic derivatives can be demonstrated in tubular epithelium during or following spontaneous or induced hemoglobinemia $(1-6)$.

Although these histological observations suggest that hemoglobin enters tubular cells as a result of reabsorptive activity, attempts to demonstrate such activity in the intact animal by physiological methods have been equivocal. Conventionally, inferences regarding hemoglobin reabsorption have been made in one of two ways: on the basis of a demonstrable threshold level of excretion $(5,7)$ or by demonstrating a difference between the rate of filtration of hemoglobin and its rate of excretion $(7,8)$. However, neither of these methods has proved satisfactory or conclusive in recent studies in man (9) and the dog (10), in which it has been shown that the threshold results largely from plasma protein binding and that the differences between rates of filtration and excretion are small or negligible.

In the present study an attempt was made to demonstrate reabsorptive activity in the intact animal (the dog) in another way: by the use of stop flow analysis (11). This method is based on the principle that, when urinary outflow is suddenly obstructed, the composition of urine trapped in metabolically active tubular segments is altered, owing to continued tubular reabsorptive or secretory activity, the effect of such alterations becoming apparent on restoration of

* Supported by a grant-in-aid (A-1971) from the National Institute of Arthritis and Metabolic Diseases, Bethesda, Md.

$\dagger$ Medical Student Fellow of The National Foundation. flow. In effect, tubular activities are exaggerated during the period when flow is stopped. This method may, therefore, be used to demonstrate (and localize) certain tubular transport activities when such activities are too small or difficult to demonstrate by other means (12-14). It was for this reason that stop flow analysis was applied to an investigation of renal hemoglobin transport in the present study.

\section{METHODS}

The stop flow method as described by Malvin, Wilde and Sullivan (11) and modified by Pitts, Gurd, Kessler and Hierholzer (12) was used. Anesthetized female dogs, weighing 12 to $30 \mathrm{~kg}$, were given infusions of 20 per cent mannitol (containing 0.85 per cent $\mathrm{NaCl}$ ), paraaminohippurate $(\mathrm{PAH})$, creatinine and hemoglobin. Autogenous hemoglobin, prepared by hemolysis of whole blood in distilled water (15), was used in all experiments. A priming dose of approximately $4 \mathrm{~g}$ of hemoglobin was given intravenously in order to saturate plasma hemoglobin-binding capacity and to induce hemoglobinuria. Hemoglobin was added to the sustaining infusion containing $\mathrm{PAH}$ and creatinine and was given at a rate of approximately $6 \mathrm{mg}$ per minute throughout the experiment. A relatively constant plasma level of free hemoglobin in excess of $100 \mathrm{mg}$ per $100 \mathrm{ml}$ (range 115 to $370 \mathrm{mg}$ per $100 \mathrm{ml}$ ) was obtained.

Urine for stop flow analysis was collected from a polyethylene catheter inserted into the right ureter. Bladder urine from the left kidney was drained by urethral catheter. Blood was collected at appropriate intervals from a femoral artery. After hemoglobin had appeared in the urine and urine flow from the right kidney had attained a minimal rate of 8 to $10 \mathrm{ml}$ per minute, three 3-minute control periods were obtained and the flow from the right kidney was stopped for a period of 4 or 8 minutes by clamping the polyethylene catheter. One minute before release of the clamp $10 \mathrm{ml}$ of inulin was injected intravenously. After restoration of flow, 25 to 40 samples of urine of approximately $1.0 \mathrm{ml}$ volume each were collected over a period of 4 minutes. Following this, three 3 -minute recovery periods were obtained. 
In 5 additional experiments urine flow was stopped by clamping the main renal artery rather than by obstructing ureteral outflow (16). In all other respects these experiments were performed in a manner similar to that described above for the ureteral stop flow experiments. An incision was made in the right flank and a catheter was inserted in the ureter. The renal artery was approached retroperitoneally and exposed by gentle dissection with minimal manipulation of both artery and kidney. A ligature was left lying loosely around the artery for purposes of identification and the skin incision was closed with metal clips. After urine flow was established and the control collection periods obtained, the incision was quickly opened and the main renal artery was clamped tightly with rubber-tipped forceps. Four minutes later the forceps was released and urine was collected from the ureter in the usual manner.

Urine and plasma were analyzed for total hemoglobin content by the benzidine method of Crosby and Furth (17); for free hemoglobin by the paper electrophoretic method of Lathem and Worley (15); for sodium in an internal standard flame photometer; and for creatinine (18), para-aminohippurate (19) and inulin (20) by conventional methods.

\section{RESULTS}

Ureteral stop flow. Twelve experiments were performed. The data from two representative experiments are presented in Figures 1 and 2. The values for hemoglobin, sodium, and $\mathrm{PAH}$ are expressed as $\mathrm{U} / \mathrm{P}$ ratios relative to the $\mathrm{U} / \mathrm{P}$ ratio for creatinine, shown at the bottom of the figure, in order to correct for changes in concentration resulting from the reabsorption of water. The concentration of inulin in urine is expressed in milligrams per $100 \mathrm{ml}$. The averages of the three control periods $\left(\mathrm{U}_{1}, \mathrm{U}_{2}\right.$, and $\left.\mathrm{U}_{3}\right)$ and the three recovery periods $\left(U_{4}, U_{5}\right.$, and $\left.U_{6}\right)$ appear as lines at the left and right of the figures, respectively. The values in between, shown in the form of curves, were obtained during the immediate four-minute period after release of the catheter and restoration of flow. The first of the serial samples collected appears at the left of the curve. Urine derived from the more distal part

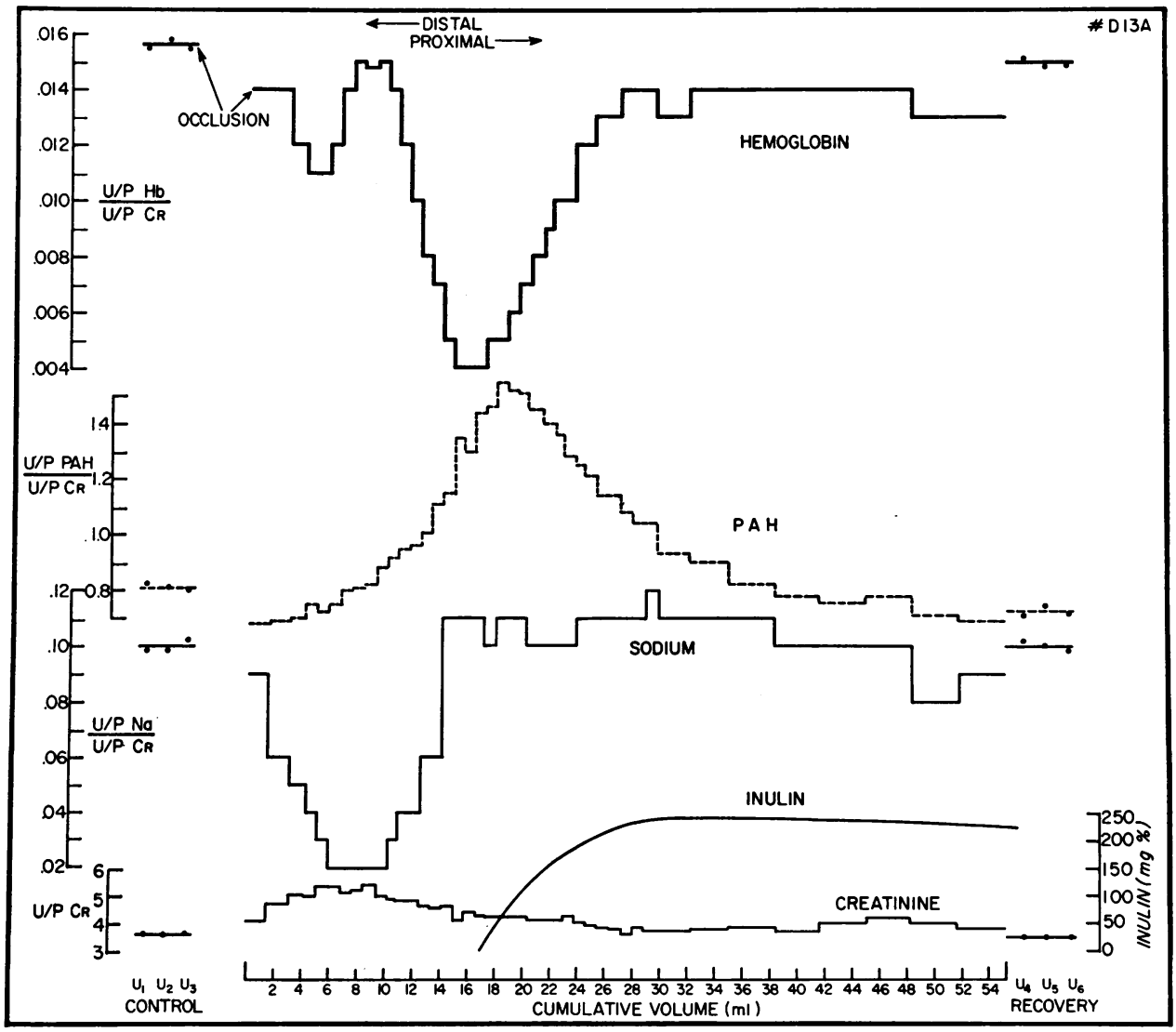

Fig. 1. URETERAl StOP FLOW EXPERIMENT. Occlusion for four minutes. 


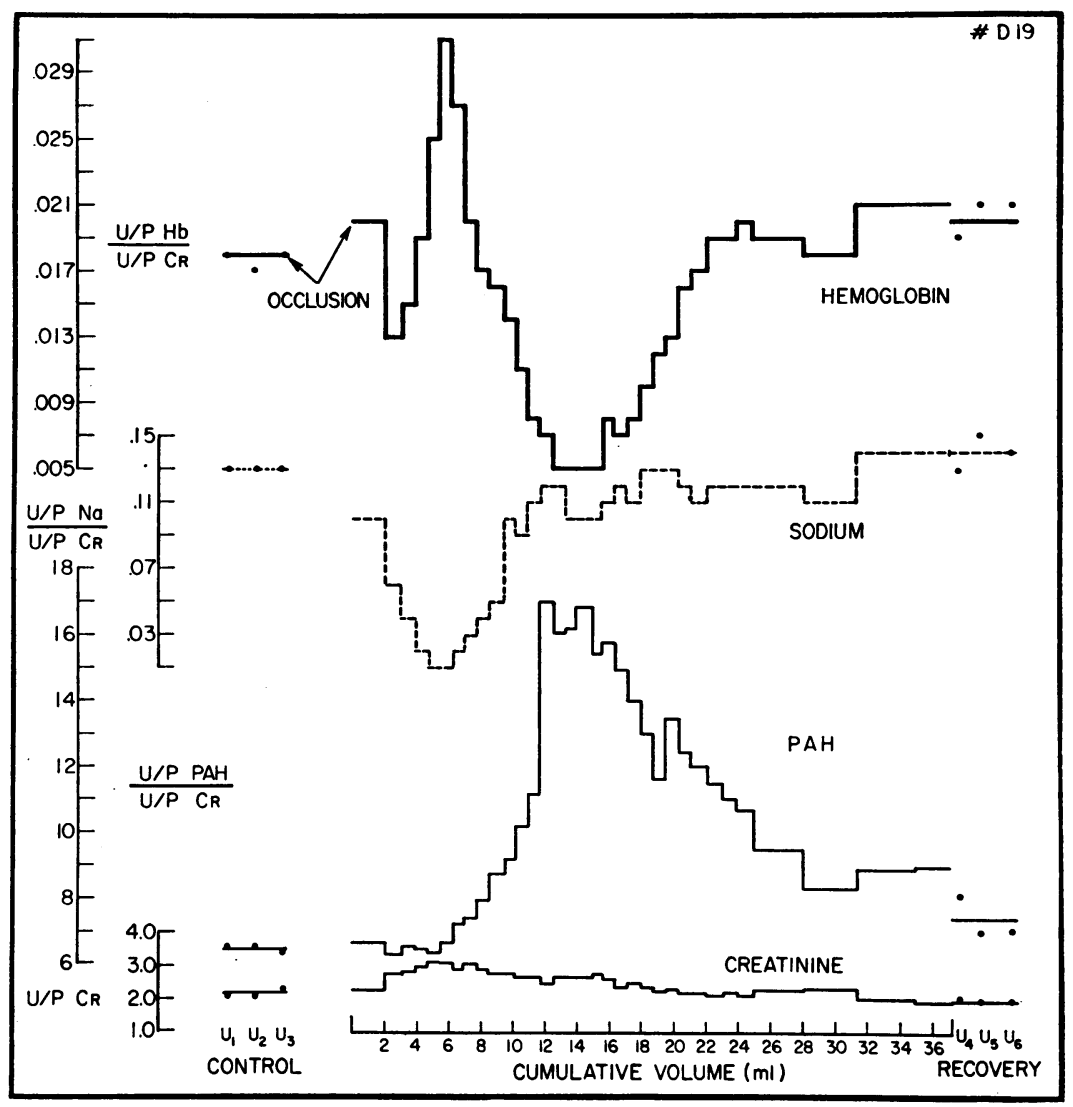

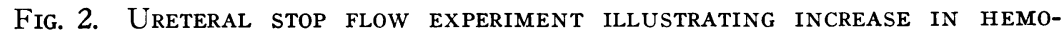
globin U/P ratio above control values in the postocclusion period. Occlusion for four minutes.

of the nephron, therefore, appears toward the left and is identified by a fall in the $U / P$ ratio for sodium; urine derived from more proximal portions appears toward the right and is identified by a rise in the $\mathrm{U} / \mathrm{P}$ ratio for $\mathrm{PAH}(11,12)$. The volume of each sample collected during the immediate postocclusion period is represented horizontally on the curves and may be obtained by reference to the cumulative volume scale at the bottom of the figures. The rising inulin concentration curve identifies the appearance of new filtrate.

The $U / P$ ratios for hemoglobin relative to creatinine appear at the top of the figures. The values plotted are for free, unbound hemoglobin only; protein-bound hemoglobin was not excreted at any time, either before or after ureteral occlusion. In all experiments the $U / P$ ratio for free hemoglobin was reduced in urine derived from the more proximal part of the nephron. This reduction coincided with the increase in the $U / P$ ratio of $\mathrm{PAH}$. However, in most experiments the maximal fall in hemoglobin concentration ${ }^{1}$ (relative $\mathrm{U} / \mathrm{P}$ ratio) was displaced somewhat distally from the maximal rise in $\mathrm{PAH}$ concentration. From the point of maximal depression, the concentration of hemoglobin increased progressivly and returned to but did not exceed control free flow values.

In all but three experiments an additional reduction in the relative hemoglobin $U / P$ ratio occurred in urine derived from the more distal part of the nephron. The change in concentration in

1 The term concentration is used interchangeably here and subsequently with the $U / P$ ratio of the substance under discussion relative to that of creatinine. A change in concentration occurring independently of water reabsorption is implicit in a change in the relative $U / P$ ratio, and it is in this sense that the term concentration is used. 
these samples was small as compared with the more proximal reduction and involved fewer samples of urine. The maximal reduction in concentration in this area was displaced somewhat distally from the maximal fall in sodium concentration.

The $U / P$ ratio for hemoglobin relative to creatinine of urine samples intermediate between those in which hemoglobin concentration was reduced approximated control values in six studies (Figure 1) and exceeded control values in six studies (Figure 2). In no instance, however, did the $U / P$ ratio for hemoglobin relative to creatinine exceed 1.0 .

No significant difference was noted in the curves obtained following ureteral occlusion for four or eight minutes.
Renal artery occlusion. The results of one illustrative experiment are presented in Figure 3. Clamping the main renal artery resulted in complete and immediate cessation of urine flow. On release of the clamp, urine flow returned immediately but at a slower rate than during the control periods, averaging approximately 60 to 70 per cent of control values during the immediate postocclusion period. In this respect arterial occlusion differed from ureteral occlusion, following which urine flow returned promptly to control levels. This difference is reflected in the smaller cumulative volume in the arterial stop flow experiments (Figure 3) as compared with ureteral stop flow (Figure 1).

Changes in hemoglobin and sodium $\mathrm{U} / \mathrm{P}$ ratios (relative to creatinine) similar to those elicited by

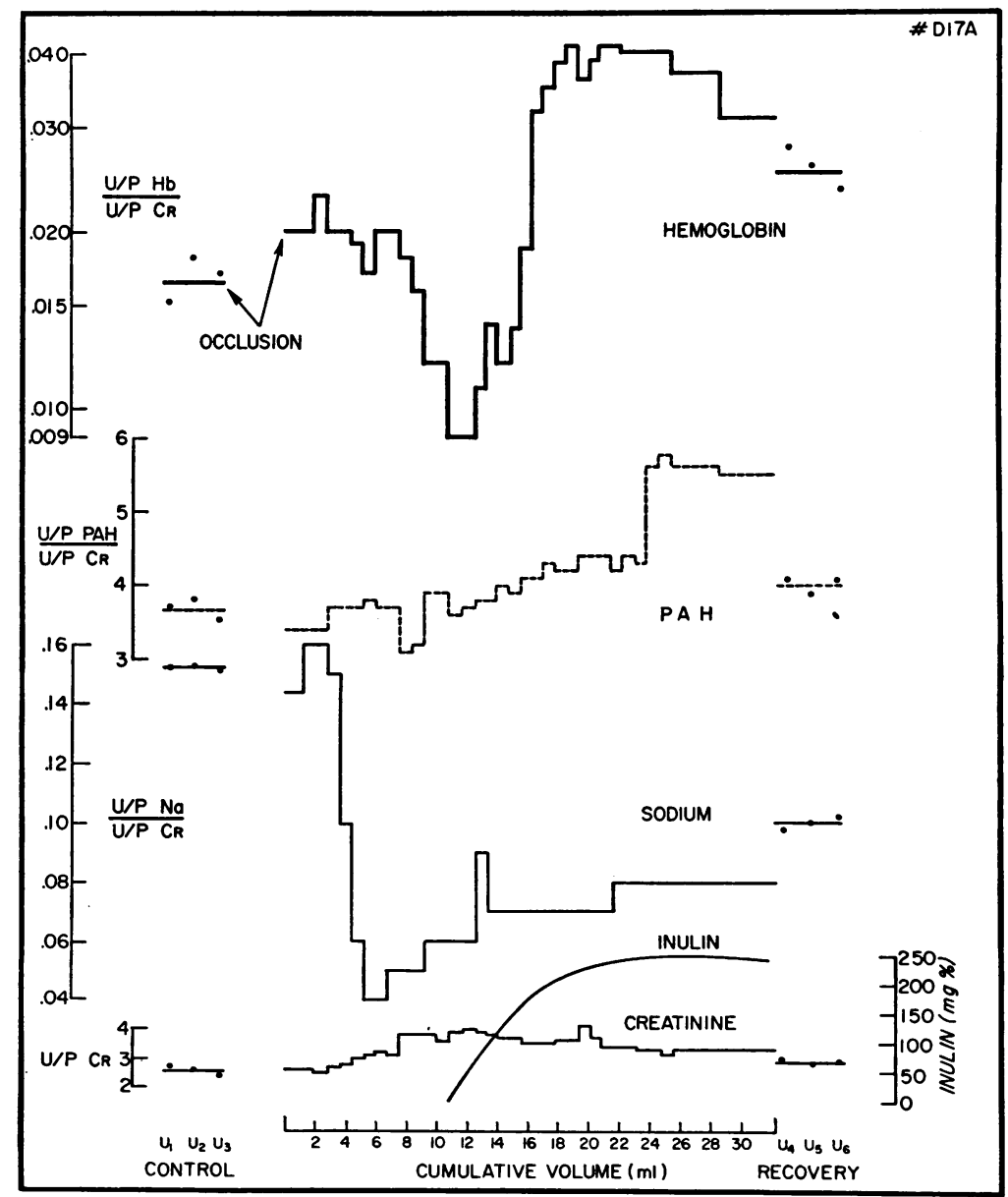

Fig. 3. Renal artery stop flow experiment. The main renal artery was clamped for four minutes. 
ureteral obstruction were obtained following arterial occlusion. The $\mathrm{U} / \mathrm{P}$ ratio for hemoglobin fell in samples of urine derived from the more proximal part of the nephron and the $U / P$ ratio for sodium fell in urine derived from the more distal part of the nephron. However, the concentration of hemoglobin in urine derived from the more distal part of the nephron did not change. The appearance of new filtrate was associated with an increase in hemoglobin $\mathrm{U} / \mathrm{P}$ ratios above control values, presumably the result of an increase in glomerular permeability secondary to cessation of blood flow and ischemia. The concentration of sodium returned toward control values but remained reduced throughout the postocclusion period. The changes in sodium concentration were similar to those described by others (16).

The $\mathrm{U} / \mathrm{P}$ ratio for $\mathrm{PAH}$ did not change, as might be expected in the absence of blood flow, until late in the curve when it began to increase in association with the appearance of new filtrate. The creatinine curve did not differ significantly from that obtained following ureteral obstruction.

\section{DISCUSSION}

The demonstration of renal tubular hemoglobin reabsorption was readily achieved in the present study by the use of the techniques of stop flow analysis. Under the conditions of urinary outflow obstruction and stasis, the concentration of free hemoglobin in urine was reduced, an effect attributable to tubular reabsorption according to the principles of stop flow analysis $(11,12)$.

The ability to demonstrate reabsorptive activity in the intact animal under these circumstances, but not by conventional free flow methods (10, 21), may be explained by assuming that the capacity for reabsorption is small and that only when contact is prolonged by stasis is hemoglobin removed from the urine in amounts sufficient to detect. This view presupposes that the property of hemoglobin reabsorption is not induced by the special circumstances of ureteral obstruction but rather, that the effects of an intrinsic, physiological reabsorptive mechanism are enhanced by these circumstances and become apparent.

The production of similar effects by renal artery occlusion supports this hypothesis. The static conditions imposed by clamping the renal artery may be assumed to operate in a manner similar to that of ureteral obstruction in reducing hemoglobin concentration by prolonging contact between trapped urine and metabolically active reabsorptive segments of the nephron. Although it has been suggested (16) that factors other than stasis may contribute to the changes elicited in urinary composition during both arterial and ureteral occlusion, there is no evidence that such factors confer upon the tubule properties not inherent therein.

In response to stasis, whether elicited by ureteral or arterial occlusion, non-uniform changes were induced in the concentration of hemoglobin in trapped urine, thus permitting an approximation of the site of reabsorptive activity. The reduction in concentration elicited was most clearly evident in urine presumably derived from the more proximal part of the nephron. Reabsorption in a proximal site may, therefore, be inferred. Since precise localization is not possible by stop flow analysis, the anatomical segments of the nephron involved cannot be identified. However, the demonstration of a proximal site is in accord with morphological studies of hemoglobin reabsorption in which this substance or its derivatives have been identified in proximal tubular epithelium $(2,3$, $6,22,23)$. Neither the present experiments nor histological studies provide conclusive evidence of reabsorption in distal parts of the nephron. Although there were suggestive distal changes noted in the present study, these were small and of uncertain significance.

The mechanism and significance of the increase in hemoglobin concentration above control values noted following ureteral obstruction in half of the present experiments (Figure 2) are not clear. An increase in concentration may suggest tubular secretion when $U / P$ ratios relative to creatinine are in excess of 1.0. However, such ratios were not observed and would not be expected with a large molecular substance like hemoglobin, even in the presence of secretion, owing to restricted diffusion across the glomerulus. The same criteria for secretion as for freely diffusible substances cannot, therefore, be applied. Whether the observed changes reflect tubular secretion or resulted from diffusion or other unknown factors cannot be evaluated from the present data alone. 
Other studies have failed to provide evidence of tubular secretion of hemoglobin $(24,25)$.

\section{SUMMARY}

Renal tubular reabsorption of free hemoglobin was demonstrated in the dog by the technique of stop flow analysis. The sequential changes in urinary hemoglobin concentration following ureteral obstruction and stasis were indicative of reabsorption in a proximal part of the nephron. Similar changes were elicited by transient occlusion of the main renal artery. Reabsorption during both ureteral and arterial occlusion was attributed to an intrinsic tubular mechanism, the effects of which were enhanced by the static conditions imposed.

\section{ACKNOWLEDGMENT}

The authors are indebted to the Misses Lucy Nelson, Carolyn Patton, and Mary Jo Hill for technical assistance.

\section{REFERENCES}

1. Ponfick, E. Experimentelle Beiträge zur Lehre von der Transfusion. Virchows Arch. path. Anat. 1875, 62, 273.

2. Allen, A. C. The Kidney: Medical and Surgical Diseases. New York, Grune and Stratton, 1951.

3. Oliver, J., MacDowell, M., and Tracy, A. The pathogenesis of acute renal failure associated with traumatic and toxic injury. Renal ischemia, nephrotoxic damage and the ischemuric episode. J. clin. Invest. 1951, 30, 1307.

4. Hampton, J. K., Jr., and Mayerson, H. S. Hemoglobin iron as a stimulus for the production of ferritin by the kidney. Amer. J. Physiol. 1950, 160, 1.

5. Newman, W. V., and Whipple, G. H. Hemoglobin injections and conservation of pigment by kidney, liver and spleen. The influence of diet and bleeding. J. exp. Med. 1932, 55, 637.

6. Rather, L. J. Renal athrocytosis and intracellular digestion of intraperitoneally injected hemoglobin in rats. J. exp. Med. 1948, 87, 163.

7. Monke, J. V., and Yuile, C. L. The renal clearance of hemoglobin in the dog. J. exp. Med. 1940, 72, 149.

8. McDonald, R. K., Miller, J. H., and Roach, E. B. Human glomerular permeability and tubular recovery values for hemoglobin. J. clin. Invest. 1951, 30, 1041.

9. Lathem, W. The renal excretion of hemoglobin: Regulatory mechanisms and the differential excre- tion of free and protein-bound hemoglobin. J. clin. Invest. 1959, 38, 652.

10. Vanderveiken, F., Gueritte, G., de Myttenaere, M., and Lambert, P. P. Effets de la liason hémoglobine-haptoglobine sur l'excretion de l'hémoglobine. J. Urol. méd. chir. 1958, 64, 136.

11. Malvin, R. L., Wilde, W. S., and Sullivan, L. P. Localization of nephron transport by stop flow analysis. Amer. J. Physiol. 1958, 194, 135.

12. Pitts, R. F., Gurd, R. S., Kessler, R. H., and Hierholzer, K. Localization of acidification of urine, potassium and ammonia secretion and phosphate reabsorption in the nephron of the dog. Amer. J. Physiol. 1958, 194, 125.

13. Kessler, R. H., Hierholzer, K., and Gurd, R. S. Localization of urate transport in the nephron of mongrel and Dalmatian dog kidney. Amer. J. Physiol. 1959, 197, 601.

14. Ginn, E., Smith, W. O., Hammarsten, J. F., and Snyder, D. Renal tubular secretion of magnesium in dogs. Clin. Res. 1959, 7, 276.

15. Lathem, W., and Worley, W. E. The distribution of extracorpuscular hemoglobin in circulating plasma. J. clin. Invest. 1959, 38, 474.

16. Brodsky, W. A., Kaim, J. T., and Carrasquer, G. The nature of urinary acidification process during transient obstruction of renal artery and ureter (abstract). J. clin. Invest. 1959, 38, 991.

17. Crosby, W. H., and Furth, F. W. A modification of the benzidine method for measurement of hemoglobin in plasma and urine. Blood 1956, 11, 380.

18. Bonsnes, R. W., and Taussky, H. H. On the colorimetric determination of creatinine by the Jaffé reaction. J. biol. Chem. 1945, 158, 581.

19. Smith, H. W., Finkelstein, N., Aliminosa, L., Crawford, B., and Graber, M. The renal clearances of substituted hippuric acid derivatives and other aromatic acids in dog and man. J. clin. Invest. 1945, 24, 388.

20. Schreiner, G. E. Determination of inulin by means of resorcinol. Proc. Soc. exp. Biol. (N. Y.) 1950, 74, 117.

21. Lathem, W. Unpublished observations.

22. De Gowin, E. L., Warner, E. D., and Randall, W. Renal insufficiency from blood transfusion; anatomic changes in man compared with those in dogs with experimental hemoglobinuria. Arch. intern. Med. 1938, 61, 609.

23. Harrison, H. E., Bunting, H., Ordway, N. K., and Albrink, W. S. The pathogenesis of renal injury produced in the dog by hemoglobin or methemoglobin. J. exp. Med. 1947, 86, 339.

24. Bieter, R. N. Albuminuria in glomerular and aglomerular fish. J. Pharmacol. exp. Ther. 1931, 43, 407.

25. Havill, W. H., Lichty, J. A., Jr., Taylor, G. B., and Whipple, G. H. Renal threshold for hemoglobin in dogs uninfluenced by mercury poisoning. $\mathrm{J}$. exp. Med. 1932, 55, 617. 